\title{
EVALUATION OF MICRO-CLIMATE EFFECTS ON SURFACING
}

\section{SEAL PERFORMANCE}

WJvdM Steyn PrEng, MSAICE ${ }^{1}$

R Briedenhann MSAICE ${ }^{2}$

\section{ABSTRACT}

Surfacing seals consist of a combination of bitumen and aggregate, and are used to provide an all-weather surfacing to protect underlying layers and provide safe access to vehicles traveling on a road. Analysis of a number of sections in Gauteng, South Africa, has shown that surfacing seals lost a large proportion of their aggregate where the road was crossed by a bridge. As all original properties of the seal components as well as the traffic on the road were similar, it was deduced that the micro-climate where the road traveled underneath the bridge should have caused this localized failure condition. In this paper the phenomenon is investigated through analysis of the micro-climate underneath the bridge, the material properties of the surfacing seal, and the combined effect of these factors on the performance of the seal. It is shown that the micro-climate can affect the performance of an otherwise suitable surfacing seal to such an extent that the performance of the seal is severely compromised. A procedure for the analysis of potential micro-climate effects is described in the paper.

${ }^{1}$ Associate Professor, Department of Civil Engineering, University of Pretoria, Pretoria, South Africa Lynnwood Road, Hatfield, 0002, South Africa

Phone: +27 124202171

Email:wynand.steyn@up.ac.za

PrEng - Professional Engineer - Engineering Council of South Africa

MSAICE - Member of the South African Institute for Civil Engineering

${ }^{2}$ Civil Engineer, Geostrada - Aurecon Group, P.O. Box 11126, Hatfield, Pretoria, South Africa Phone: +27 124273071

Email: riaanab@gmail.com 


\section{SUBJECT HEADINGS}

Surfacing seals, micro-climate, aggregate loss

\section{INTRODUCTION}

Surfacing seals consist of up to three layers of aggregate that are bound with a sprayed layer of bitumen (Fig. 1). Typically, surfacing seals are used for traffic levels between 125 and 20000 vehicles per day in South Africa. The three main functions of a surfacing seal are to provide a waterproof cover to the underlying pavement, to provide a safe, all-weather dustfree riding surface for traffic with adequate skid resistance and to protect the underlying layer from the abrasive and destructive forces of traffic and the environment (TRH3 2007). In South Africa the environmental conditions are such that roads experience between 60 per cent (coastal areas) and 80 per cent (north-western parts) of the possible duration of sunshine during a year. Average annual ambient temperatures of between $13{ }^{\circ} \mathrm{C}$ and $22^{\circ} \mathrm{C}$ are experienced, with maximum air temperatures of up to $45^{\circ} \mathrm{C}$ and minimum temperatures of as low as $-8^{\circ} \mathrm{C}$. The effect of these temperature ranges during construction on the performance of surfacing seals is the topic of this paper. One of the prime reasons for aggregate loss (raveling) on surfacing seals is found when the binder is too cold and therefore too viscous when the aggregate is applied to the sprayed binder, causing inadequate bonding between the road surface and the aggregate (Webb 2010; TRH3 2007). Binder cooling can result from either too cold initial temperatures (outside the scope of this paper) or from contact with cool road surfaces and subsequent rapid cooling and increase in viscosity of the binder. 


\section{Problem definition}

The paper evaluates a phenomenon that was observed on a number of pavements in the Gauteng province of South Africa, where localized areas of aggregate loss (raveling) were identified on recently sealed pavements where these pavements were crossed by bridges (Fig. 2). This is potentially a major problem on a sealed surfacing, as the loss of aggregate leads to an area where the skid-resistance of the surfacing is much lower than that of the surrounding pavement, and therefore it can lead to severe safety problems.

\section{Fig. 1. Typical cross section through a single surfacing seal.}

\section{Fig. 2. Typical indication of aggregate loss underneath bridge.}

\section{Scope and purpose}

The scope of this paper includes an evaluation of the phenomenon of raveling on a surfacing seal below a bridge on a freeway in the Gauteng province of South Africa. It utilizes information on the diurnal temperatures of road surfacings in South Africa (based on the location of the site), together with actual temperature measurements and the use of a solar chart to evaluate the locations of shadows on the road surface and compare these with the existence of raveling of the surfacing. The purpose of the paper is to demonstrate the effect of the micro-climate created by the bridge shadow on the road surface, the effects of this on the seal performance and a method to identify the potential for such a micro-climate before it occurs on the road.

\section{BACKGROUND}

\section{Surfacing seals}


The binder used for a specific surfacing seal needs to conform to a number of requirements, mainly dependent on the traffic levels and environmental conditions where the surfacing seal is to be constructed. The service life and performance of the seal depends on good adhesion between the aggregate, binder and road surface and the durability of the binder under the ambient environmental conditions. The binder should provide both adhesive and cohesive strength. Essentially it should initially be fluid enough (low viscosity) to allow it to be sprayed onto the surface and cover the pavement, and for the aggregate to be embedded sufficiently into the binder layer, and then become viscous enough to prevent the aggregate from being pulled out or whipped from the surface (TRH3 2007).

The construction process for a surfacing seal consists of spraying of bituminous binder at a specific temperature to ensure that the existing pavement is penetrated and that a layer of binder with a specific minimum thickness is provided, in order for the selected aggregate size to be adequately embedded into this bitumen layer and that adhesion forces between the bituminous binder and the aggregate can therefore withstand the applied traffic forces.

The required temperature for spraying the bitumen is prescribed and typically indicated on the Bitumen Test Data Chart (Fig. 3). If the temperature is compromised it will lead to a lack of embedment and potential raveling.

Fig. 3. Bitumen Test Data Chart for 80/100 Pen bitumen used on this project, indicating effects of temperature on spray viscosity.

\section{Environmental effects}

The typical environmental effects that affect the construction success and performance of surfacing seals include ambient temperatures and moisture conditions. Extremely hot weather conditions typically lead to reduction in cohesion, while cold weather leads to brittle binder 
and resultant aggregate loss and cracking. Excessive exposure to ultra-violet radiation results in accelerated binder ageing while humidity variations affect the evaporation of volatiles in the binder (TRH3 2007).

The ThermalPADS package is used in South Africa to determine the road surface temperature at locations in the country (ThermalPADS 2007). ThermalPADS is based on a combination of actual weather records from weather stations located across the country and the use of relationships between the air temperature, longitude and latitude of the location and asphalt temperature profiles (Viljoen 2001; Denneman 2007).

This paper specifically investigates the temperature effects below the bridge as this microclimate causes a difference in temperature below and adjacent to the bridge during construction.

\section{Micro-climate}

Various definitions exist for micro-climate. Most definitions agree that micro-climate can be defined as a local atmospheric zone where the climate differs from the surrounding area (Perry and Symons 1991). Micro-climates of interest to road engineers are typically found in urban areas where engineering structures consisting of asphalt, concrete and bricks either absorb the sun's energy, heat up, and reradiate that heat to the ambient air, or shadow other infrastructure causing lower temperatures. Road surface conditions vary both spatially and temporally along a road. Thermal maps can be developed for specific road surfaces, indicating the expected micro-climate along a specific road.

The diurnal temperature changes of a road surface are affected by the prevailing weather conditions, which influence the time of the maximum and minimum road surface temperatures and also the amplitude of the diurnal change. Differences in exposure to direct

sunlight, as well as the duration of any direct sunlight on the road surface, plays a major role 
in the micro-climate on a specific location on the road. Sky-view factor is the terminology used to relate the theoretical maximum incoming solar radiation to the actual figure, with 0 indicating that none of the sky is visible to the surface and 1 indicating no obstructions. Apart from changes in cloud cover, the sky-view factor will depend on the presence of structures (buildings and bridges / road furniture) and vegetation (i.e. tall trees). The sky-view factor at a specific point varies due to the height of the sun in the sky and the angle of incidence of the incoming solar radiation, leading to the sky-view factor to be affected by seasons also (Perry and Symons 1991).

In this paper the micro-climate created on a road pavement through the shadows cast by a bridge structure onto the surface of the road is evaluated. The potential effect of cloud cover is excluded in this analysis, as well as any effect from vegetation, as no tall trees are typically close enough to freeways (the type of road evaluated in this paper) in South Africa to affect the micro-climate directly, and cloud cover would cause a bridge, trees or other obstructions to have little effect.

\section{Seals and micro-climate effects}

During construction a bituminous binder of one type will be used for the whole production process, and binders will thus not be changed when the spray-truck is applying the binder underneath a bridge. If the temperature underneath the bridge is thus lower than the surrounding area, due to the shadow cast by the bridge, the same aggregate penetration will not be obtained under the bridge than for the remainder of the pavement. The typical recourse is that the rollers can be used to apply more roller passes to the section of road under the bridge, to therefore ensure with sufficiently high stresses applied to the aggregate that the aggregate actually embed deep enough into the bitumen to ensure that a good bond exists. However, if the sprayed binder cools off too quickly and the viscosity of the binder on the 
pavement increases too much, even a high number of roller passes will not be adequate to ensure that the aggregate forms a sufficiently strong bond with the layer of bitumen. Too much compaction may also lead to crushing of the aggregate and excessive embedment of the aggregate into the bitumen layer adjacent to the bridge micro-climate area.

Uniformity in binder application for seals depends on the viscosity of the binder, which is described in the temperature-viscosity relationship. The viscosity of bitumen is dependent on the temperature (Read and Whiteoak 2003; Illston and Domone 2001). The factors influencing the adhesion of bitumen are divided into four groups: aggregate properties, bitumen properties, interactive mix properties and external influences. The main external influence (considered in this paper) is the ambient temperature, as all of the other parameters are the same below and away from the bridge. Senadheera and Yazgan (2008) published the data shown in Fig. 4 indicating the typical exponential cooling function of hot sprayed bitumen. As the binder is sprayed on top of the road surfacing, a colder road surface will cause quicker cooling of the sprayed bitumen than a hot road surface.

\section{Fig. 4. Typical decrease in temperature of hot sprayed bitumen (after Senadheera} and Yazgan 2008).

\section{EXPERIMENTAL DESIGN}

\section{Scope of experiment}

The hypothesis was developed that the observed aggregate loss under the bridge was due to the micro-climate under the bridge being sufficiently different than that away from the bridge to cause the viscosity of the binder used in the surfacing seal to be unable to provide the required adhesion during construction to cover the aggregate sufficiently, and therefore the aggregate was not properly fixed to the pavement surfacing. Traffic on the surfacing caused 
pull-out forces that were higher than the strength of the adhesion between the aggregate and the bituminous binder, and therefore the aggregate were removed from the surfacing.

\section{Parameters}

The important parameters for the investigation in this study were the climatic conditions and specifically the temperature conditions related to the location of the bridge structure and the bearing of these on the road surface temperatures and the resultant bitumen temperature. The actual binder properties used in the surfacing seal is a secondary parameter, as the same binder was used for the whole road resurfacing and thus the anticipated changes in microclimate should have caused the major differences in performance. The other seal parameters (aggregate type, spray rates, compaction effort, etc) were all constants (in the comparison between the bridge and locations away from the bridge) and are not temperature sensitive and are thus treated as tertiary parameters in this analysis.

\section{Procedure}

In order to evaluate the hypothesis and determine the probable causes of the phenomenon, the following experimental design was developed. The micro-climate underneath the bridge where the aggregate-loss occurred was measured using i-buttons located in the shade on the pavement surface (micro-climate pavement temperature), on the bridge pillars in the shadow (micro-climate ambient temperature) and in the sun on the pavement surface (general climate pavement temperature).

The historical temperature (ambient and pavement surface) fluctuations for the area in which the bridge is located were obtained using the ThermalPADS software (ThermalPADS 2007). A database of 14 years of daily temperatures was available for the site. These temperatures (designated "general" in the figures and analyses) enabled the typical range of 
temperatures for the area and the time of year that the construction was conducted (April) to be determined. The average daily temperatures were used in the analyses, as most of the minimum temperatures occurred during the night, when no construction will take place.

Thereafter the typical temperature-viscosity relationships for the binder used in these surfacing seals (80/100 penetration bitumen) were determined (Fig. 3) (Colas 2008).

Once the micro-climate and the binder properties were known, the data were combined and inferences were drawn from the combined data set. However, it still needed verification that the area where the raveling occurred was where the lower road temperatures were found. In order to verify that the micro-climate was the major reason for the aggregate loss phenomenon, the location of shadows on the pavement surfacing underneath the bridge (thus the area of the micro-climate) was determined using an architectural model indicating the angle with which the sun will meet the road in the area of the bridge and these locations were correlated with the location of the aggregate loss underneath the bridge. The use of this model is viewed as vital in the connection between the actual measured temperatures and the anticipated conditions during the year on the specific location.

The specific site selected for this investigation was located on a national road south-west of Pretoria in the Gauteng province.

\section{Shade projection technique}

As the earth orbits the sun, it appears on earth, as if the sun is moving relative to the planet with respect to time of year and not only by the time of day. In this regard residential properties are typically oriented with their main windows in the direction of the sun (i.e. north in the southern hemisphere and south in the northern hemisphere) to allow sunlight into the rooms during the winter months, but to prevent too much sun from entering the room during the warmer summer months (Fig. 5). 


\section{Fig. 5. Relative sun projection during the year in South Africa (adapted from}

\section{Grobbelaar, 1993).}

As the positions of the sun relative to the earth varies with the time of year, it will have an impact on the shade positions caused by obstructions such as bridges, deep cuttings and trees, to name but a few. By considering the apparent movement of the sun, it is inevitable to suggest that the shadow will move accordingly. Architects have noticed this phenomenon and developed tools to aid in the appropriate design for buildings. A solar chart that allows the architect to determine the angle to the horizontal at which the sunlight will be projected is shown in Fig. 6. The method for using the solar chart in determining the shade projection and sun position relative to a building (or bridges and other obstructions) is summarized as follows:

- Determine the longitude and latitude of the location where the solar information is required;

- Determine the extremes of the location of the angle of the sun to the horizontal by reading off the values for June 22 and December 22 from Fig. 6. Conduct this exercise for the whole day and plot the angle of the sun through the day;

- Determine the location, height, length and width, and the orientation with regards to true north of the bridge, and;

- Draw the geometry of the bridge together with the angles of the sun and determine the location of the shadow of the bridge during the year.

\section{DATA ANALYSIS}




\section{Collected data}

The objective of the data analysis was to determine whether the difference (if any) between the pavement temperatures underneath the bridge shadow (micro-climate) and away from the bridge shadow (general climate) could have played a significant role in the observed aggregate loss.

\section{Bitumen temperature analysis}

In Fig. 7 the data collected for the general (based on a database of 14 years) pavement surface temperatures are shown together with the measured micro-climate temperature data. The data are shown for the month of April, as this is the month during which the microclimates were monitored and also the month during which the construction of the seal took place. When comparing the two sets of data statistically, an average difference of $9^{\circ} \mathrm{C}$ between the general data and the micro-climate data is found.

Fig. 6. Solar chart to aid in the design of buildings (adapted from Grobbelaar, 1993).

The temperature-viscosity data for the $80 / 100$ Pen bitumen used in the surfacing seal is shown in Fig. 8 (also see Fig. 3 for the Bitumen Test Data Chart). The required spray temperature for bitumen in a single seal (Colas, 2008) is between $165^{\circ} \mathrm{C}$ and $175^{\circ} \mathrm{C}$. A minimum road surface temperature of $25^{\circ} \mathrm{C}$ is required to use this $80 / 100$ Pen bitumen in a surfacing seal (TRH3 2007). Evaluation of Fig. 8 indicates that, while it is applicable to use the $80 / 100$ Pen bitumen for constructing the surfacing seal during April outside of the bridge micro-climate, it would not be appropriate to use it inside the bridge micro-climate (without modifying the binder). 
Fig. 7. Comparison between Micro-climate and General Pavement surface temperature during April.

Fig. 8. Typical temperature-viscosity relationship for 80/100 Pen bitumen (Colas, 2008).

As indicated, the average temperature difference between the general climate and the micro-climate is $9^{\circ} \mathrm{C}$. Analyses of the temperature-viscosity relationships for a $80 / 100$ Pen bitumen indicates that this $9^{\circ} \mathrm{C}$ temperature difference translates into an average difference of $400 \mathrm{~Pa} . \mathrm{s}$ in the viscosity of the bitumen. (The assumption made is that the cooler surface temperature of the micro-climate (under the bridge) will also lead to a faster cooling down of the sprayed bitumen).

The option exists to cut the bitumen back using petroleum-based cutters to effectively change the viscosity of the bitumen binder during spraying. However, this is done for the bulk binder, and if the temperature of only the micro-climate areas is lower than the required temperatures, then this option is not viable on a macro-scale, as the binder sprayed onto the remainder of the pavement will have an inadequate viscosity due to the warmer surface temperature.

The data in Figs. 7 and 8 indicate the minimum and maximum viscosities required for the 80/100 Pen bitumen, as well as the pavement surfacing temperature for the General climate and the micro-climates. Although only a $9^{\circ} \mathrm{C}$ difference exists in the temperatures, this translates to a higher difference in the viscosity due to the logarithmic relationship that exists between the temperature and viscosity of the bitumen.

The effective outcome of the lower temperature of the binder when the aggregate is spread onto the pavement is shown schematically in Fig. 9. Inadequate embedment onto the cooler 
binder leads to the adhesion between the binder and aggregate to be inadequate to keep the aggregate bound into the binder layer, and aggregate loss occurs.

Fig. 9. Schematic indication of the effect of the lower binder temperature on the surfacing seal and aggregate embedment.

By using the solar chart (Fig 6) the shade projection for the selected bridge passing over the freeway was calculated for the three positions of the sun relative to earth. These three positions represent the Summer Solstice, Vernal and Autumn equinox and Winter Solstice.

A section through the bridge and a long section of the freeway passing underneath are shown in Fig. 10.

\section{Fig. 10. Shade projections for bridge over freeway.}

The distance values at the top of Fig. 10 are measured values from the bridge, and the patch where the aggregate is stripping relative to the bridge(s). The blue line represents the shade during June along the length of the road surface, the red line for December and the green line for March and September. The blue, green and red lines are determined by using the solar chart, for the dates shown in the figure. The purple line represents the length of patch where the stripping of aggregate is taking place. The area where the blue, green and red lines overlap is an area of road surface that is in the shade for the whole year. Through elimination, the shaded part under the bridge is the only difference that there is between the macro- and the micro-environments (Fig. 10). The minor differences between the three overlapping lines and the purple line, can be due to simplification of the model. The position of the shadow at the time of construction is most important in this analysis. The seal was 
constructed during April (close to the end of March and autumnal equinox (southern hemisphere)) and the purple line (indicating the location of aggregate loss) are centered on the green lines indicating the shade during the equinox.

In terms of potential solutions to the problem, the first important aspect is to obtain information regarding the actual micro-climates below bridge shadows. If these temperatures are adequate for the aggregate to sufficiently embed into the binder, the aggregate loss should not occur. If the micro-climate temperature is too low, but the temperatures are marginally close to the required temperature, the phenomenon can be limited through increased roller action directly after spreading of the aggregate on the hot binder in the area of the bridge. This should assist in improved embedment of the aggregate. Increased compaction of the aggregate into the sprayed bitumen can also be achieved through lower roller speeds (increased contact time) underneath the bridge. However, if it is clear that the temperatures in the micro-climate area are too low for proper construction of the seal, localized application of cut-back binder or emulsions should be investigated to ensure that such surfacing failures are prevented.

\section{PRACTICAL APPLICATION}

Based on the analysis conducted in this paper, the following is recommended as a practical application of the solar chart and bitumen test data charts to evaluate whether or not raveling can be expected based on inadequate road temperatures during seal construction.

First the actual road temperatures in the location need to be determined. This can typically be done using a resource such as ThermalPADS which is based on environmental conditions (specifically temperatures) and asphalt temperature-viscosity relationships over a number of years. In case such a resource is not available, actual temperatures need to be measured on the site. 
Secondly the location and dimensions of the bridge are used with the solar chart (Fig. 6) to determine the location of shadows underneath the bridge during the planned construction period (especially if this is done a while before construction and cannot be observed in real time). The actual surfacing temperatures of the pavement are measured inside and outside the shadow of the bridge.

Thirdly the viscosity properties of the bitumen to be used in the surfacing seal need to be evaluated at the lower expected temperature under the bridge to determine whether or not the expected temperatures are too low to enable an effective seal to be constructed (Bitumen Test Data chart in Fig. 3).

Finally a decision needs to be taken regarding the final application of binder for the surfacing seal. This can require a postponement of the construction under the bridge to a time slot later in the day when the road may be hot enough, or the use of a different type of binder underneath the bridge or the use of heavier rollers to ensure adequate penetration of the aggregate into the binder layer under the bridge. Combinations of these options are also possible. The designer should be very careful when different binders or rollers are used to prevent compromising the remainder of the surfacing seal outside of the specific microclimate.

\section{CONCLUSIONS}

Based on the information discussed in this paper, the following conclusions are drawn:

- The micro-climate underneath bridges can, due to the shadow of the bridge, cause pavement surface temperatures to be too low for adequate aggregate embedment when constructing surfacing seals; 
- These lower binder temperatures can lead to aggregate loss in areas where the embedment of aggregate into the binder was too little due to increased viscosity of the binder, and

- The problem can be alleviated by analyzing the potential decreases in surfaces temperatures during the planning phase and allowing for localized increased compaction of the surfacing seal during construction.

\section{ACKNOWLEDGEMENTS}

The paper is based on the final year undergraduate dissertation of the second author and the support of the University and various roads departments in providing information and conducting the research is acknowledged.

\section{REFERENCES}

Colas, (2008). “80/100 Bitumen Penetration Grade Bitumen.” Product data sheet 2008/1, Colas South Africa.

Denneman, E. 2007. "The application of locally developed pavement temperature prediction algorithms in performance grade (PG) binder selection". 26th Southern African Transport Conference (SATC) 2007, Pretoria, South Africa.

Encyclopedia Brittanica, 2010. http://www.britannica.com/EBchecked/topic/380278/ microclimate - accessed on 20 September 2010.

Grobbelaar, P.A., 1993. Building Construction \& Graphic Standards. South Africa: The Natal Witness Printing \& Publishing Company (Pty) Ltd.

Illston J.M. and Domone P.L.J. (eds). (2001). “Construction materials: Their nature and behaviour." 3rd ed. London \& New York: Spon press 
Perry, A.H. and Symons, L.J. 1991. Highway meteorology. E\&FN Spon. UK.

Read, J. and Whiteoak, D. (2003). "The Shell bitumen handbook". Fith Edition, Shell UK Oil Products Limited.

Senadheera, S. and Yazgan, B. (2008). "Incorporating construction and performance conditions to develop a testing protocol to select seal coat aggregate-binder combinations" $1^{\text {st }}$ International Sprayed Sealing Conference, ARRB, Adelaide, Australia.

ThermalPads. (2007). "ThermalPADS Version 1.0" www.csir.co.za. CSIR Built Environment, Pretoria, South Africa.

TRH3. (2007). “Technical Recommendations for Highways. Design and construction of surfacing seals - TRH3.” SA National Roads Agency, Pretoria, South Africa.

Viljoen, A.W. (2001). "Estimating asphalt temperatures from air temperatures and sky basic parameters. Report CR-2001/78. CSIR, Pretoria, South Africa.

Webb, Z.L. (2010). "Seal Coat and Surface Treatment Manual”. Manual Notice 2010-1. Texas Department of Transportation, Texas, US. 


\section{FIGURE CAPTIONS}

Figure 1 Typical cross section through a single surfacing seal.

Figure 2. Typical indication of aggregate loss underneath bridge

Figure 3. Bitumen Test Data Chart for $80 / 100$ Pen bitumen used on this project, indicating effects of temperature on spray viscosity

Figure 4. Typical decrease in temperature of hot sprayed bitumen (after Senadheera and Yazgan 2008).

Figure 5. Relative sun projection during the year in South Africa (Grobbelaar, 1993).

Figure 6. Solar chart to aid in the design of buildings (Grobbelaar, 1993).

Figure 7. Comparison between Micro-climate and General Pavement surface temperature during April

Figure 8. Typical temperature-viscosity relationship for 80/100 Pen bitumen (Colas, 2008)

Figure 9. Schematic indication of the effect of the lower binder temperature on the surfacing seal and aggregate embedment

Figure 10. Shade projections for bridge over freeway 


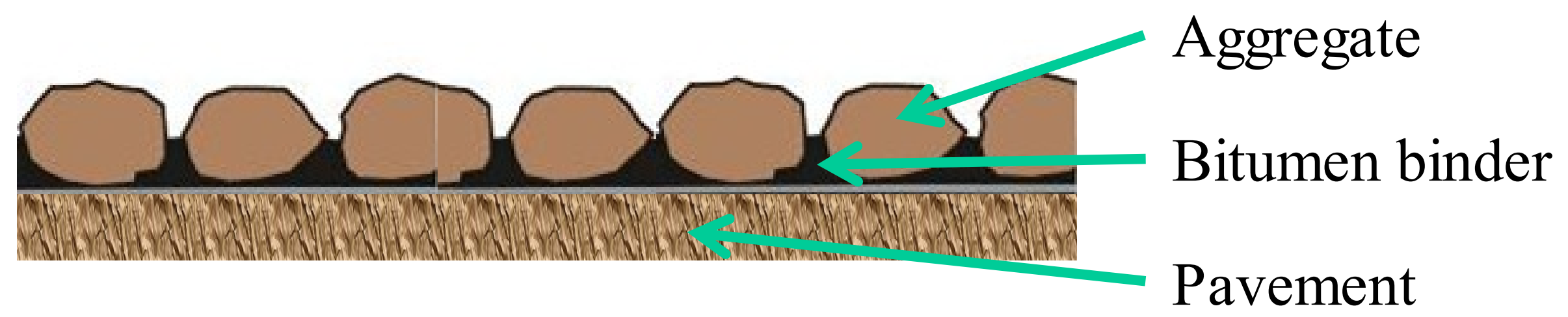




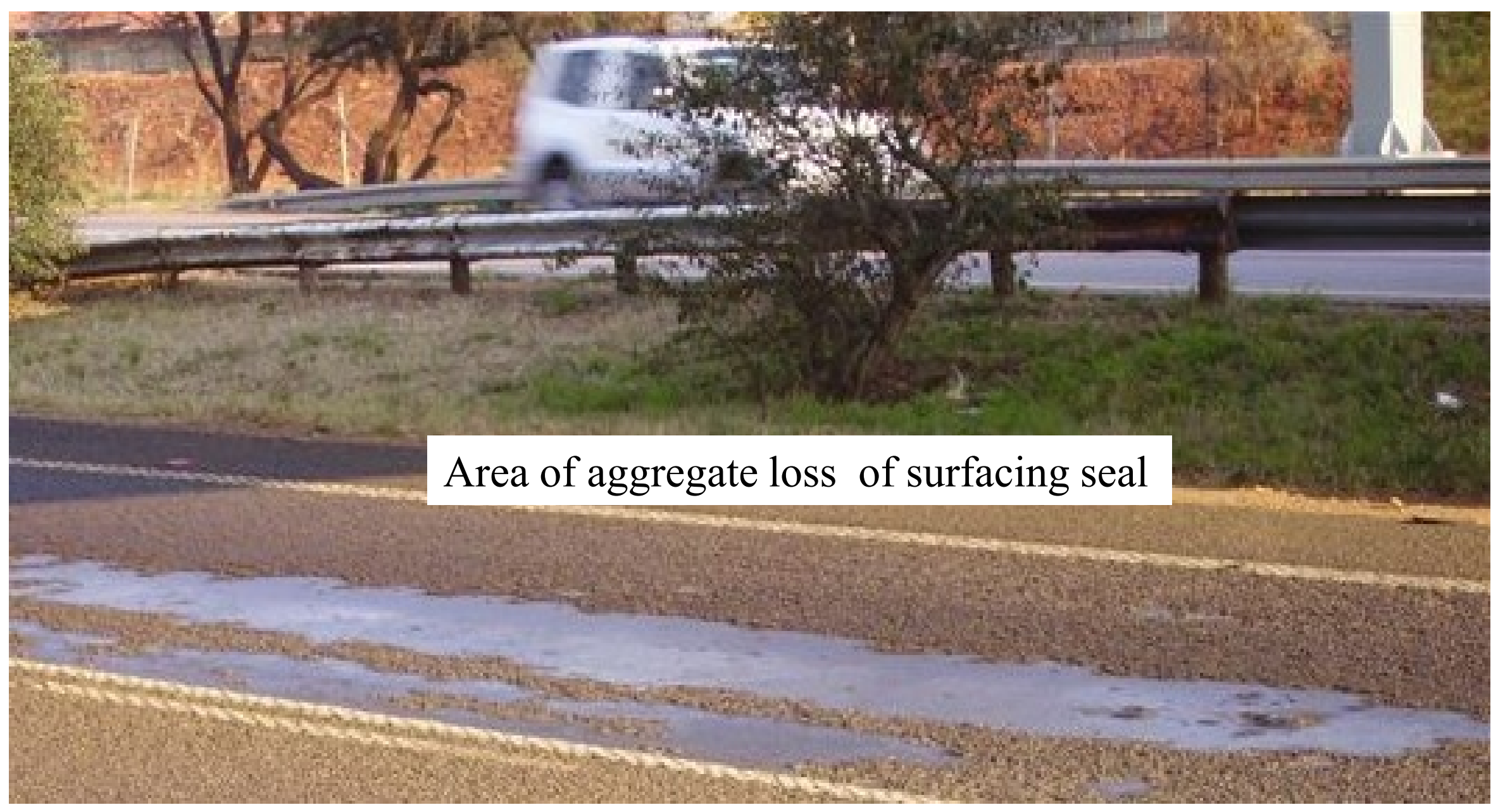




\section{) LJXUH}

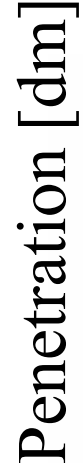

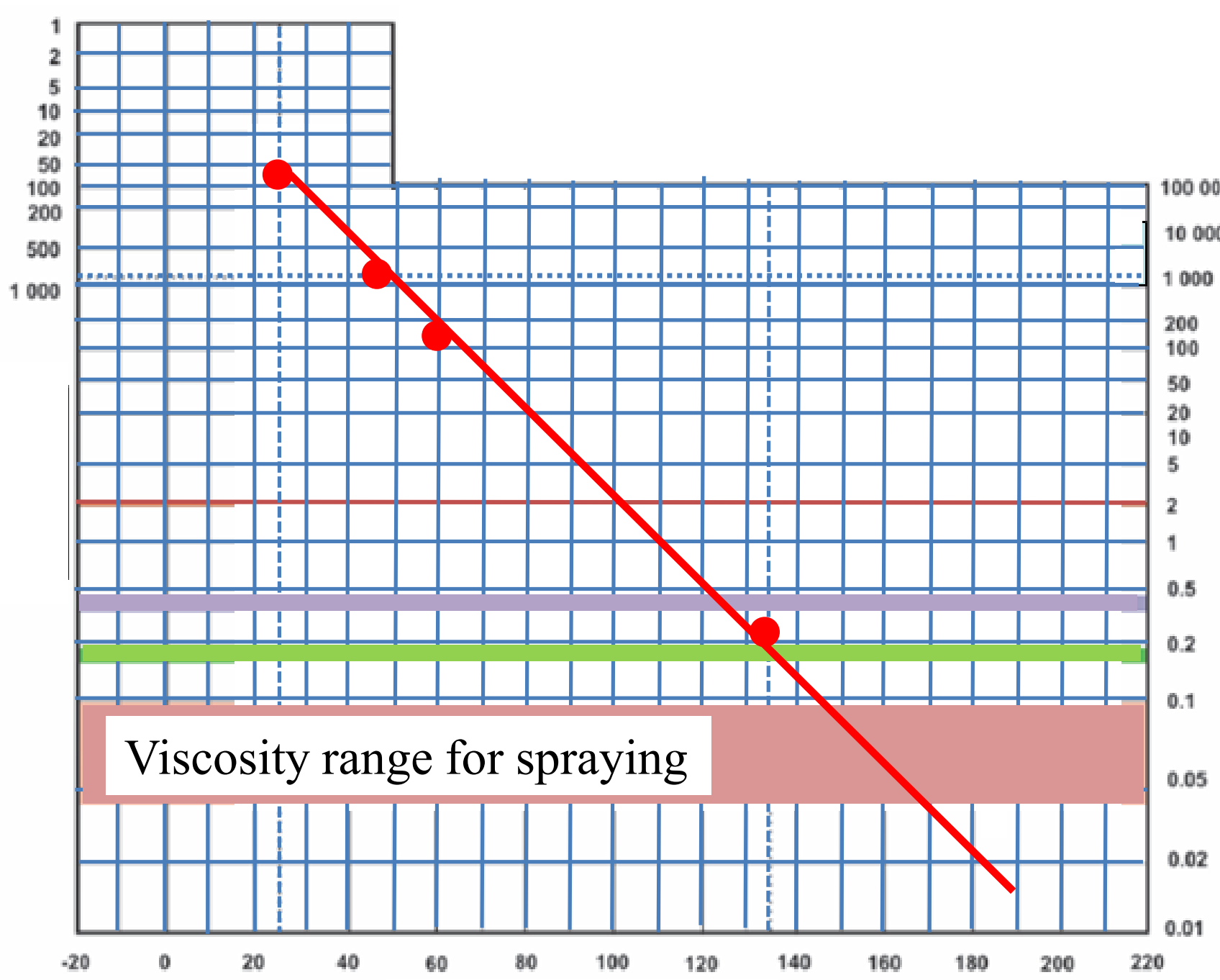

Temperature[ C] 


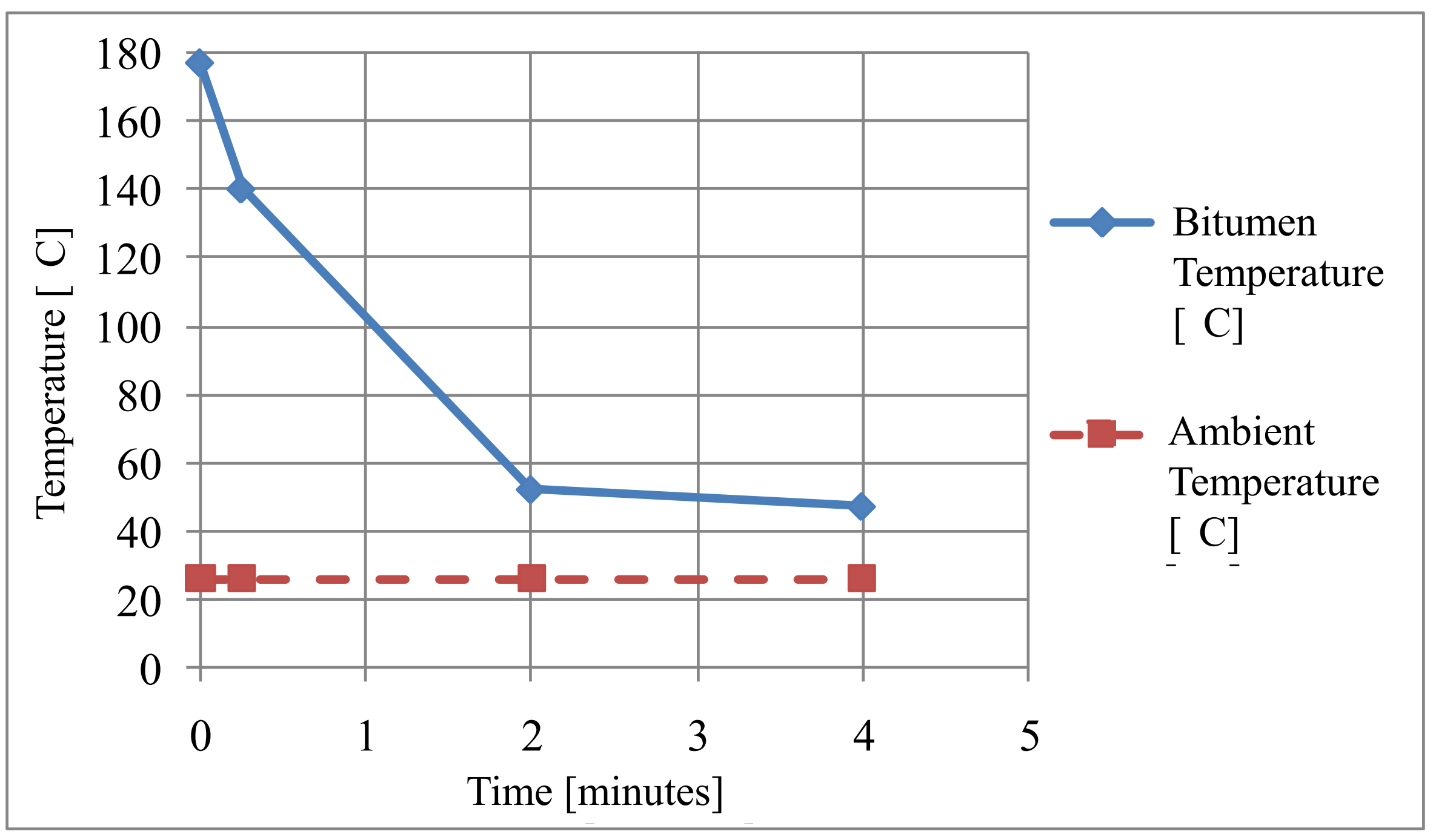




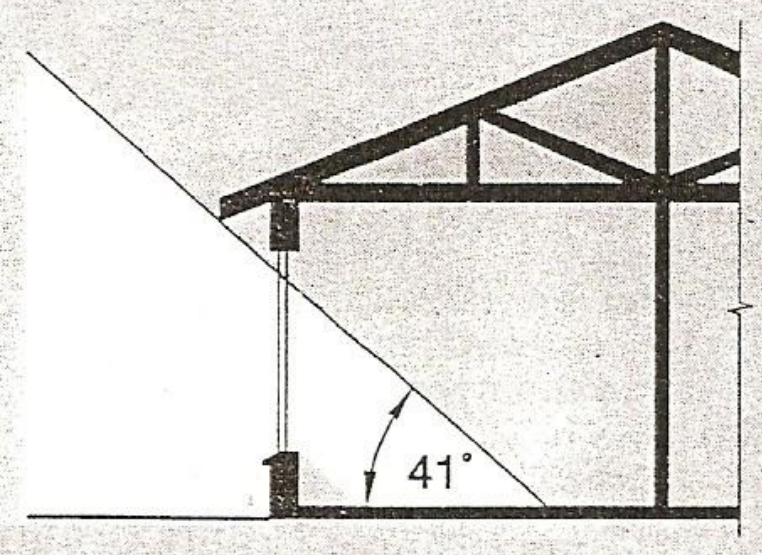

Sectional elevation of a room showing the extent of sun penetration at noon on the 22nd of June.

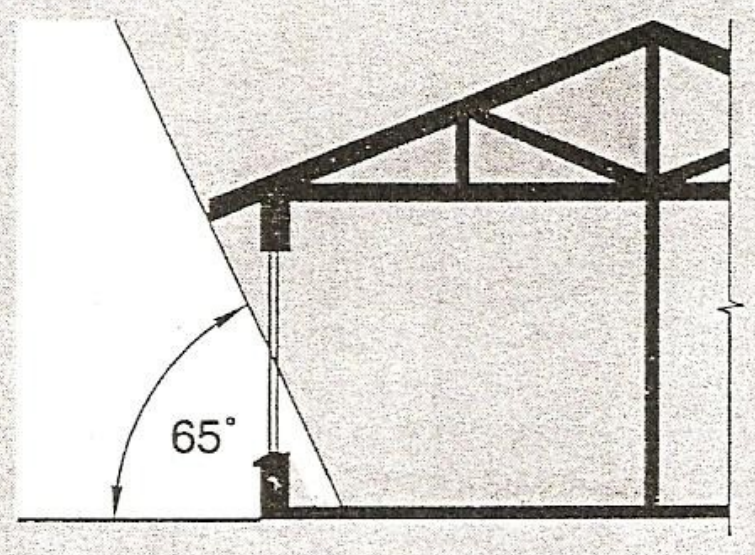

Sectional elevation of a room showing the extent of sun penetration at noon on the 21 st of March and the 23 rd of September.

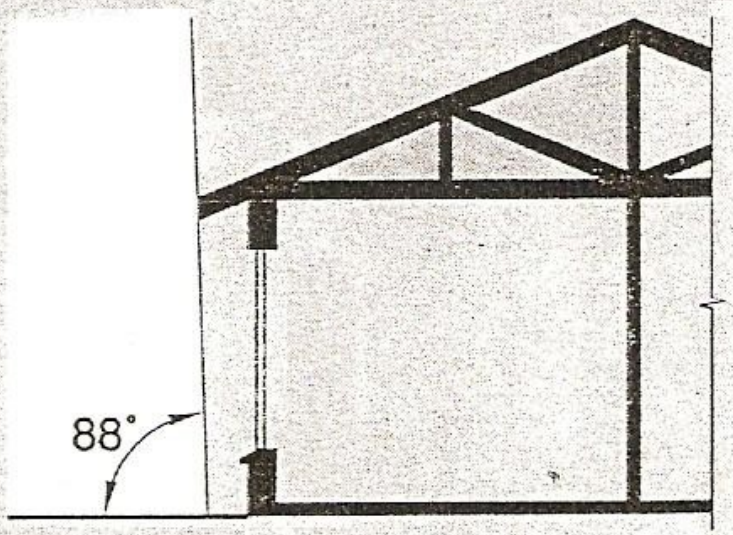

Sectional elevation of a room showing no sun penetration at noon on the 22nd of December. 


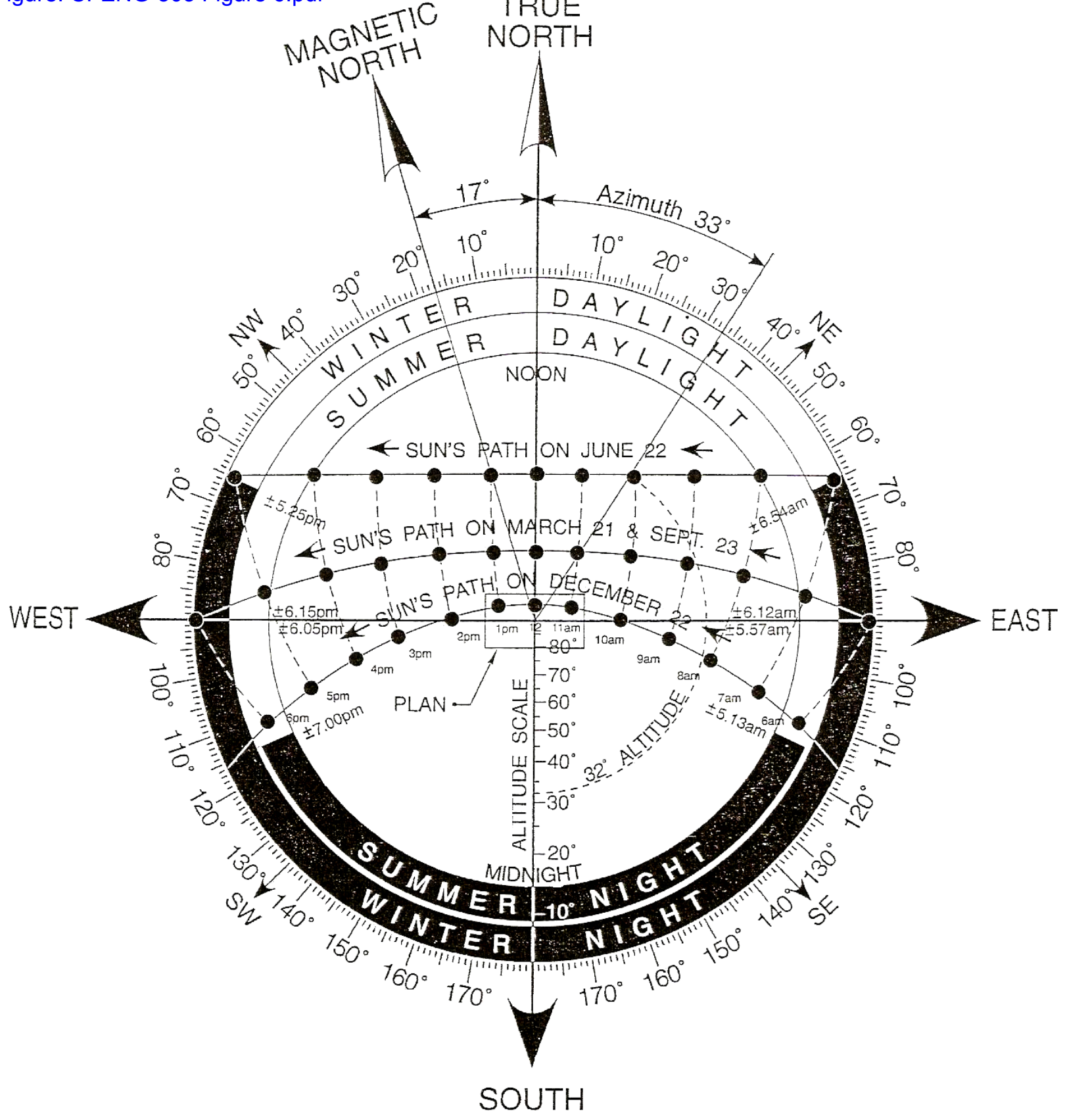




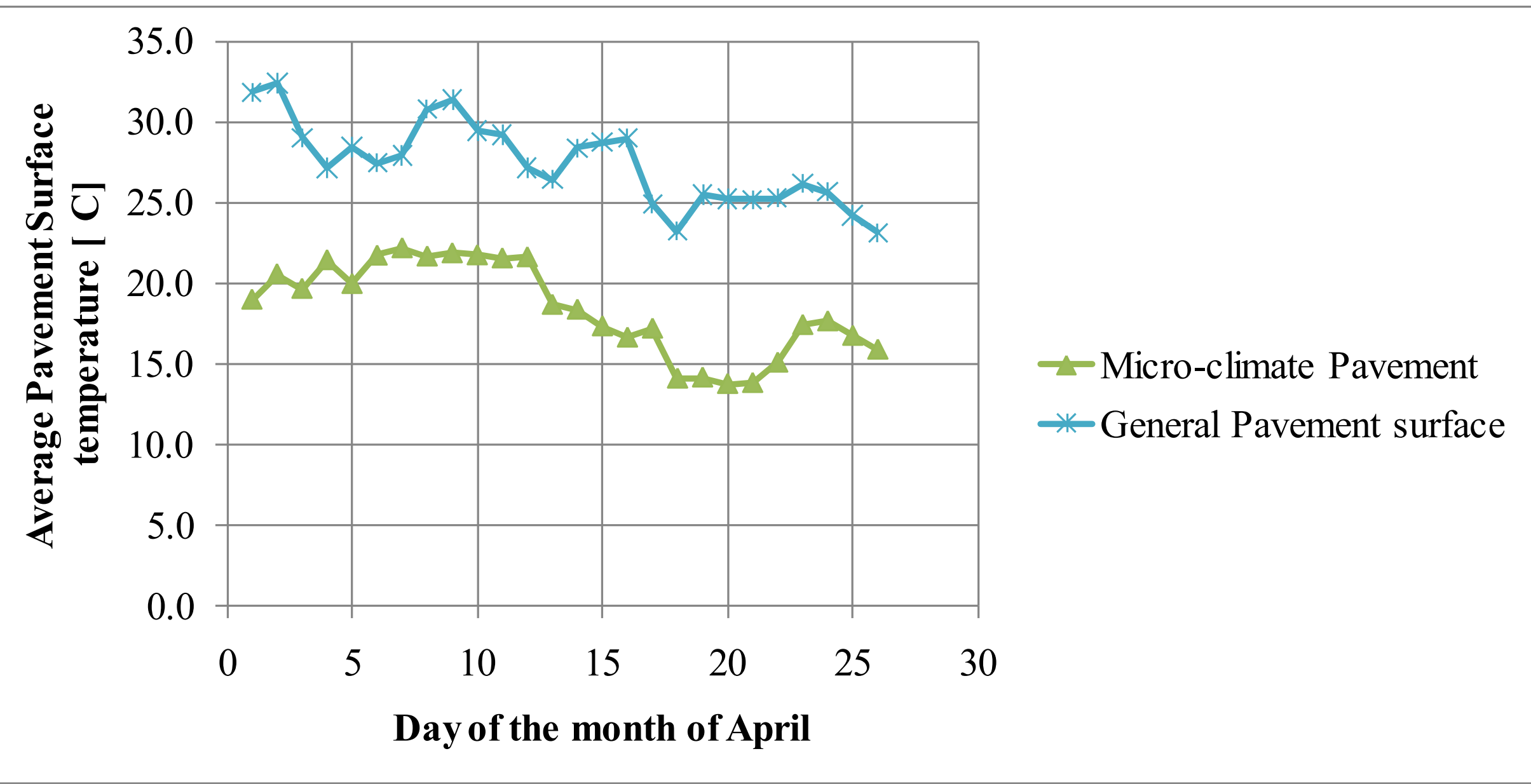




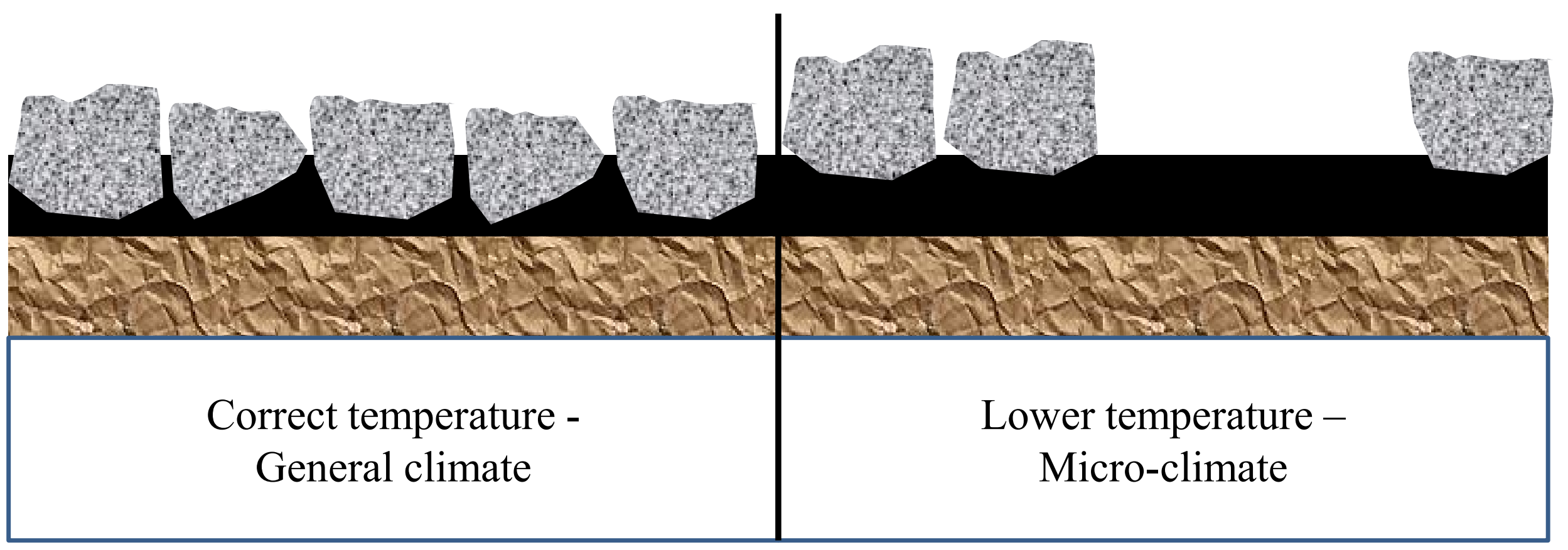




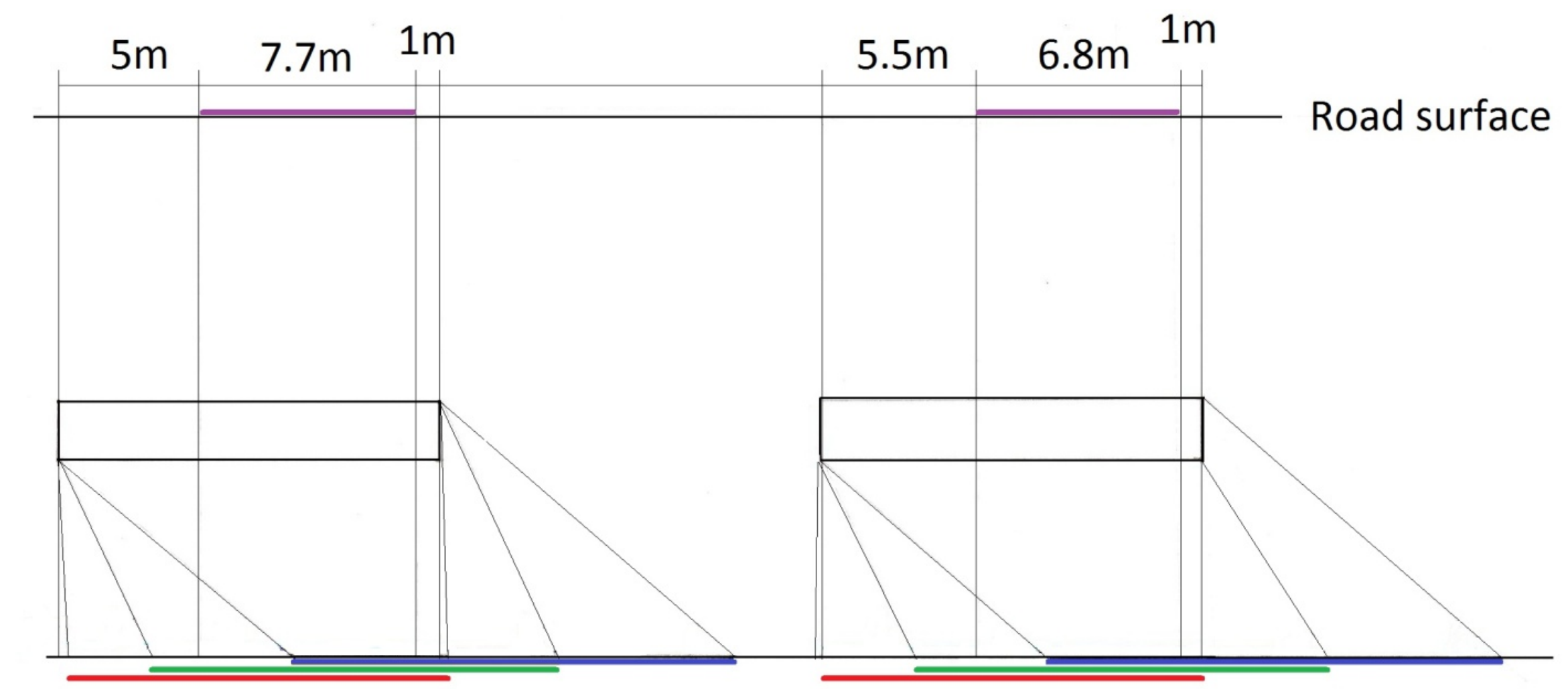

Measured aggregate loss Shade 21 March \& 23 September
Shade 22 June

_ Shade 22 December 